\title{
A new technique for remote location of unknown caves and deep-seated faults by unmanned aerial systems (UAS)
}

\section{Нов метод за дистанционно откриване на неизвестни пещери и дълбокозалягащи разломи от безпилотни летателни системи (БЛС)}

\author{
Yavor Shopov ${ }^{1,2,3}$, Krisia Petkova ${ }^{4}$, Ognian Ognianov ${ }^{5}$ \\ Явор Шопов ${ }^{1,2,3}$, Крисия Петкова ${ }^{4}$ Огнян Огнянов \\ ${ }^{1}$ Sofia University “St. K1. Ohridski”, University Centre for Space Research and Technologies, General Physics dept.; \\ E-mail: yyshopov@yahoo.com \\ ${ }^{2}$ Medical University of Sofia, Medical physics and biophysics dept., 2 Zdrave str., Sofia \\ ${ }^{3}$ Durban University of Technology, Institute for Systems Science, South Africa \\ ${ }^{4}$ Caving Club "Academik" - Ruse \\ ${ }^{5}$ Institute for Space Research and Technologies, Bulgarian Academy of Sciences, Sofia
}

\begin{abstract}
Here, for the first time in Bulgaria, we demonstrate that aerial survey of the terrain with a coaxial thermal and visible camera mounted on an UAS can detect much larger number of entrances to underground cavities and deep seated faults than a detailed systematic ground survey by experienced personnel. Thus geophysical problems are solved with these remote sensing methods. It is extremely promising and reveals great opportunities for improving techniques for location of unknown caves and deep seated faults to a much higher level. Obtained results are a significant step forward in the state-of-the art.
\end{abstract}

Keywords: caves, thermal camera, thermal imaging.

The aim of this work is to develop and apply a new innovative technology for remote detection and location of unknown caves and deep-seated faults by using thermal vision and UV imaging. It is extremely helpful to expand cave and deep-seated faults exploration in new regions. It will be very helpful to find new caves in hardly accessible regions and even on other planets (Shopov, 2017; Shopov et al., 2019b).

Development of this innovative technique is subject of the International Program on Remote Location of Caves (RLC) of the Commission on Physical Chemistry and Hydrogeology of Karst (Shopov et al., 2021) of the International Union of speleology (UIS) and this work is a part of it. The aim of this program is to develop a technology for remote location of new caves by thermal infrared camera mounted on an unmanned aerial system (UAS) and to make survey for location of new unknown caves by this technique (Shopov, 2013, 2017, 2019). First results of the program were presented during the EuroSpeleo forum 2019 (Shopov, 2019; Shopov, Ognianov, 2019; Shopov et al., 2019b).

Recently we made the most successful survey for remote detection of unknown caves. On 10 and 11
April 2021, we captured 3436 images from 7 flights over 4 different polygons located in the Sboryanovo National Historical-Archaeological Reserve - the territory of the World Heritage Sveshtari tomb, Bulgaria. We captured simultaneously the same part of the terrain in the visible and the thermal infrared area of the spectrum from an Unmanned Aerial System (UAS). This UAS has integrated aligned visible and thermal cameras recording the same area of the surface. Half of the obtained images are in the visible and half in the thermal infrared (TIR) area of the spectrum. This allows superposition of the visible and TIR images, allowing obtaining of integrated images with the high resolution of the images from the visible camera, containing important data from the much lower resolution thermal camera (Shopov et al., 2019a). Such integrated images are extremely helpful and important for detection and location of new unknown caves if environmental temperature is highly different from the temperature of the cave air coming out of cave entrances.

Almost all previous studies of the possibilities of remote location of caves with thermal infrared cameras are made on previously known caves and are aimed on 
demonstration of the potential to locate caves (Rinker, 1975; Judson et al., 2008; Wynne et al., 2008; Muhlestein, 2012; Baroň, et al., 2013), rather than to make thermal infrared survey for location of new caves. The aim of our study is to develop a technology for remote location of new caves by thermal infrared camera mounted on a UAS and to make survey for location of new unknown caves by this technique (Shopov, 2013, 2017). For this purpose, we used:

\section{Terrain mapping from drone in visual band for 3D reconstruction}

Small pixel size (of 2.91 centimetres) gave us very detailed reconstruction. With such model we can find even smallest positive and negative landforms (cave entrances). Detailed visual ortophoto (like this on Fig 1b) produced from this mapping is valuable information source to check suspicious thermal images against detailed visual image for potential cave entrances.

Figs. 1a, b represent almost the same terrain. In the frames of the instrumental error of the used GPS device cave entrances of 6 caves: 1036, 1020, 1035, 441, "Nova vlyavo" and 442 coincide with the corresponding remotely located entrances $11.8,10,11.4,11.2,11$ and 11.1.

For maximum precision of digital models, we made a series of images of the nadir with a high degree of overlap in the horizontal $(80 \%)$ and in vertical (70\%) directions, covering the entire area surveyed. Acquired images serve as inputs to "computer vision" software and generate a point cloud of $\mathrm{x}, \mathrm{y}, \mathrm{z}$ coordinate to further generate Digital Surface Model (DSM), digital orthophoto and 3D surface models.

Finding of cave entrances from thermal images is done by comparing them with their corresponding visible images. The thermal cameras of drones, unlike ground thermal cameras, are designed only for searching for objects but not for temperature measurements. Therefore, the drone's thermal camera automatically recalibrates the colour scale of each image to achieve maximum thermal contrast of the image to detect objects with a minimal temperature difference from the environment. For this reason, the thermal images obtained with them have no colour thermal scale and no linear scale. In them, the hottest areas of the image are marked in white, and in descending order of temperature, respectively, in yellow, orange, red, purple, blue and black, which are the coldest areas in the frame (Figs. 1c, d). Thermal images obtained with a drone do not contain any information about the temperature scale they depict, as well as any values of temperature and the size of the space which is captured. This information could only be extracted from a 3D terrain model. The same applies for visible photos like the one in Fig. 1b.

\section{Thermal imaging from UAS}

Aerial thermal images (like this on Figs. 1c, d) are primary source of information for remote cave location (Baroň et al. 2013; Shopov 2013; Shopov, Ognianov,
2019; Shopov et al., 2019a, b; Shopov et al., 2021). Main benefit from UAS usage is ability to move onto strict programmed trajectory and make pictures with equal intervals and programmed camera orientation. These options are most important requirements for processing with photogrammetry software.

Used ground resolution allows us to distinguish objects only several tens $\mathrm{cm}$ in size from altitude of 95 $\mathrm{m}$. Temperature difference of target from surrounding landscape is visualized on obtained thermal images (Fig. 1c, d). In addition, our UAS with thermal camera is equipped with GPS, so every picture store coordinates in the file. Cave location was measured by manual detection and comparison of hot spots on the thermal images with the corresponding ground features on the visible orthophoto images of the same part of the ground. Used UAS has two coaxial cameras with the same field of view. One of them is thermal, while

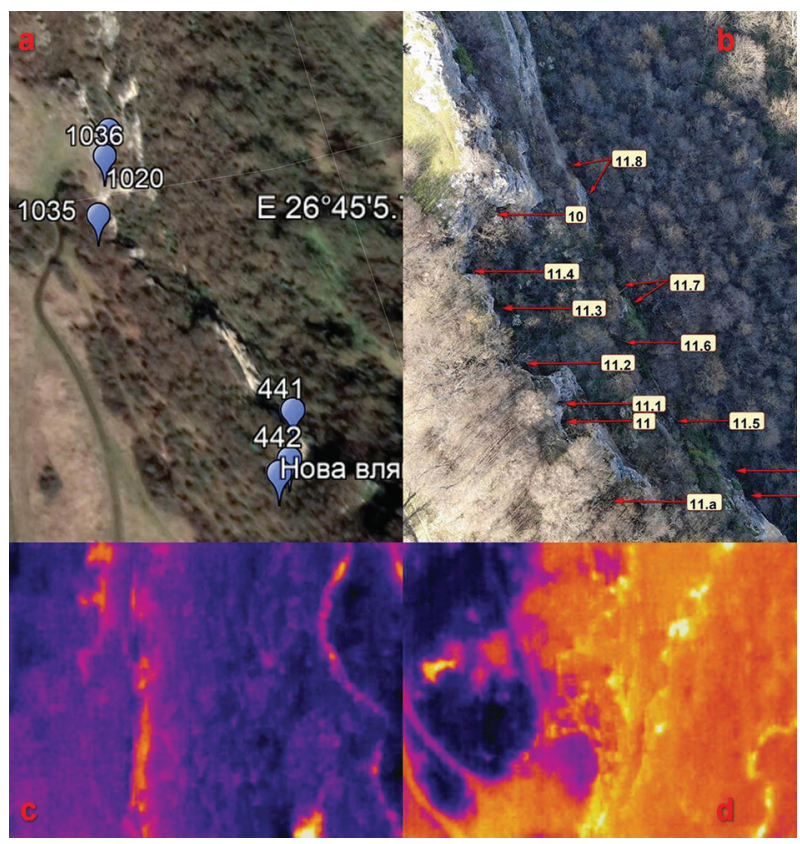

Fig. 1. Caves entrances of unknown caves and deep-seated faults localized by a thermal infrared camera (photo by Shopov and Petkova): $a$, entrances of the known caves in polygon 1 located on the Google map from March 2019 using GPS coordinates of the cave entrances taken by A. Jalov. Uncertainty of measurement of these GPS coordinates is bigger than $20 \mathrm{~m}$ (all these cave entrances are under the escarpment and are shifted with over $20 \mathrm{~m}$ to the left on the image); $b$, small part of the entrances of underground cavities and deep-seated faults located by thermal camera from UAS on April 10, 2021; c, thermal image of deep-seated faults (orange). The hottest areas of the image are marked in white, while colder ones in descending order of temperature, respectively are marked in yellow, orange, red, purple, blue and black, which are the coldest areas in the frame; $d$, thermal image of caves entrances aligned along deepseated faults (yellow) taken from UAS flying $95 \mathrm{~m}$ above the ground. The hottest areas of the image are marked in white, while colder ones in descending order of temperature, respectively are marked in yellow, orange, red, purple, blue and black, which are the coldest areas in the frame. 
the other is high resolution Hasselblad visible camera build-in a common housing. This ensures simultaneous capturing of equivalent thermal and visible images. But during the thermal survey of the terrain (6:016:11 a.m.) it was too dark to allow obtaining of sharp visible photos. So, we had to make second authentic survey of the same terrain from the same height later on the same day in order to obtain good visible images for preparation of Digital Surface Model (DSM), digital orthophoto and 3D surface models. Hopefully during both flights we had excellent flight conditions, which allow us to produce fine sets of thermal and visible orthophotos like these on Figs. 1b, c, d.

From 13 entrances remotely located with the thermal camera in the orthophoto on Fig. $1 \mathrm{~b}$ only 6 correspond to known caves (Fig. 1a). Only 8 caves are known so far in the studied polygon 1 "Demir Baba Teke" territory. Our thermal survey located 57 entrances of underground cavities and deep-seated faults in the same terrain. We expected that some of them are deep-seated faults because their shape is prolonged and very narrow (Figs. 1c, d) unlike this of cave entrances, which are always more or less round and do not extend to a significant length on the ground. Indeed, several large fractures have openings on the ground of the studied terrain.

Our following ground survey of the studied polygon found 8 entrances of new caves and two deepseated faults. Discovery of these unknown caves was proved by measuring GPS coordinates, photography and thermal imaging of the entrances of all found caves and their comparison with those documented in the Main Card-index of Bulgarian Caves for the same area. Only those caves whose maps and descriptions are indexed in this card-index are considered to be known caves in Bulgaria. Three of the discovered new caves are potentially habitable and are interesting for archeologic studies. Previous ground survey of the same terrain during the last 50 years located only 9 another caves.

Obtained results require further extensive ground survey to locate all thermal anomalies on the ground and to check their character: are they cave entrances or are just outlets of the air coming from large, closed underground cavities. In both cases it is necessary to measure their precise GPS coordinates on the ground to locate them precisely on topographic maps.

\section{Conclusions}

Here we first demonstrated that aerial survey for remote location of caves with coaxial pair of thermal and visible cameras mounted on a UAS can detect much greater number of entrances of underground cavities and deep-seated faults than detailed systematic ground survey by experienced personnel. Studied polygon 1 "Demir Baba Teke" along the Krapinets river valley, has been subject of detailed systematic ground survey by Bulgarian Speleological Society for several years, although this aerial survey detected several times greater number of cave entrances within hours. It demonstrates that using of UAS integrated with coaxial TIR and visible cameras is extremely prospective and reveals great possibilities to raise the level and sophistication of techniques for location of unknown caves to a much higher level. Obtained results are a significant step forward in the-state-of-the-art of the location of unknown caves and deep-seated faults.

Acknowledgements: This research was funded by National Science Fund of Bulgarian Ministry of Education and Science with research grant DN14/4 from 2017 to Y. Shopov. We thank to Alexey Jalov for providing GPS coordinates of the cave entrances and useful discussions.

\section{References}

Baroň, I, D. Bečkovský, L. Míča. 2013. Infrared thermographic survey of pseudokarst sites in the fysch belt of outer West Carpathians (Czech Republic). - Proc. 16th ICS, vol. 3. Brno, Czech Republic, 227-230.

Judson, J., T. Wynne, C. Titus, G. Diaz. 2008 On developing thermal cave detection techniques for Earth, the Moon and Mars. - Earth and Planet. Sci. Lett., 272, 240-250.

Muhlestein, K. N. 2012. Detecting Thermal Infrared Radiation from Cave Openings using Thermography. PhD Thesis, Univ. Texas at San Antonio.

Rinker, J. N. 1975. Airborne infrared thermal detection of caves and crevasses. - Photogrammetric Engineering and Remote Sensing, 41, 1391-1400.

Shopov, Y. 2013. Activity report of commission on physical chemistry and hydrogeology of karst of International Union of speleology (UIS). - UIS Bulletin, 56, 1, 18-19.

Shopov, Y. 2017. Using thermal vision cameras for remote location of caves on Mars for immediate shelters for astronauts and storage chambers. - J. Aeronaut. Aerospace Engin., 6, 2, 64; http://dx.doi.org/10.4172/2168-9792-C1-016.

Shopov, Y. 2019. Remote location of caves on Mars and the Moon - first step to the settlement on other planets. - Proc. 13th EuroSpeleo Forum, 26-29 September 2019, Dolni Lozen, Sofia, p. 81.

Shopov, Y., O. Ognianov. 2019. Remote location of caves by thermal cameras. - Proc. 13th EuroSpeleo Forum, 26-29 September 2019, Dolni Lozen, Sofia, p. 80.

Shopov, Y., O. Ognianov, A. Filipov, I. Ivanov. 2019a. Development of technology for remote location of unknown underground cavities and deep-seated rockslides by unmanned air systems (UAS). - J. Physics, Confer. Series, 1368, 032032; https://doi.org/10.1088/1742-6596/1368/3/032032.

Shopov, Y., O. Ognianov, I. Ivanov. 2019b. Development of technology for remote location of unknown underground cavities and deep-seated rockslides by unmanned air systems (UAS). - Proc. 13th EuroSpeleo Forum, 26-29 September 2019, Dolni Lozen, Sofia, p. 83.

Shopov, Y., K. Petkova, O. Ognianov. 2021. Progress report of the International programme for techniques for remote location of caves (RLC). - UIS Bulletin, 63-1, 18-22.

Wynne, J., T. N. Titus, Ch. Drost, R. S. Toomey, K. Peterson. 2008. Annual thermal amplitudes and thermal detection of Southwestern U. S. Caves: Additional insights for remote sensing of caves on Earth and Mars. - Lunar and Planet. Sci., 39, 2459. 